\title{
Hidrotermia e radiação UV-C no controle de patógenos de manga e melão
}

\author{
Fernanda Varela Nascimento ${ }^{1}$, Murilo César dos $\operatorname{Santos}^{1}$, Rosa Maria Valdebenito-Sanhueza ${ }^{1,2}$, Vinícius Adão \\ Bartnicki ${ }^{1}$
}

${ }^{1}$ Proterra Engenharia Agronômica Ltda. BR116, 7320, S2, 95200-000, Vacaria, RS. ${ }^{2}$ Pesquisadora do CNPq. Autor para correspondência: Rosa Maria Valdebenito-Sanhueza (rosamaria@proterra.agr.br)

Data de chegada: 06/08/2014. Aceito para publicação em: 03/11/2014.

$10.1590 / 0100-5405 / 2024$

\section{RESUMO}

Nascimento, F.V.; Santos, M.C.; Valdebenito-Sanhueza, R.M.V.; Bartnicki, V.A. Hidrotermia e radiação UV-C no controle de patógenos de manga e melão. Summa Phytopathologica, v.40, n.4, p.313-317, 2014.

As doenças de pós-colheita são, em geral, de difícil controle e são responsáveis por perdas significativas de manga (Mangifera indica L.) e melão (Cucumis melo L.) no Brasil. Os principais patógenos pós-colheita do melão são Alternaria alternata, Fusarium pallidoroseum e Myrothecium roridum, enquanto que na manga são Colletotrichum gloeosporioides e Lasiodiplodia theobromae. O objetivo deste trabalho foi avaliar a sensibilidade dos propágulos destes patógenos aos tratamentos de hidrotermia e de radiação UV-C. Suspensões de conídios e discos de micélio de cada patógeno foram submetidos aos tratamentos de hidrotermia a 50,55 e $58^{\circ} \mathrm{C}$ por 15 e $30 \mathrm{~s}$ e de radiação UV-C nas doses de $0,330 \mathrm{~kJ} \mathrm{~m}^{-2}, 0,660 \mathrm{~kJ} \mathrm{~m}^{-2}$ e $1,320 \mathrm{~kJ} \mathrm{~m}^{-2}$. Após os tratamentos e incubação por 72 e $48 \mathrm{~h}$, foram avaliados o número de unidades formadoras de colônias (UFCs) e o crescimento micelial dos patógenos, respectivamente. Os tratamentos apresentaram eficiência distinta entre os propágulos e os patógenos. O controle de UFCs e do crescimento micelial de $C$. gloeosporioides e $L$. theobromae foi superior a $88 \%$ com água aquecida a $55{ }^{\circ} \mathrm{C}$ ou $58{ }^{\circ} \mathrm{C}$, independente do tempo de tratamento. Para os mesmos patógenos, a maior dose de radiação, $1,320 \mathrm{~kJ} \mathrm{~m}^{-2}$, controlou acima de $96 \%$ das UFCs. Entretanto, o controle do crescimento micelial destes patógenos com radiação UV-C foi inferior quando comparado ao uso de água aquecida a $55^{\circ} \mathrm{C}$ ou $58^{\circ} \mathrm{C}$. O controle de UFCs de A. alternata, M. roridum e F. pallidoroseum foi superior com os tratamentos de água aquecida a $55^{\circ} \mathrm{C}$ por $30 \mathrm{~s}, 58^{\circ} \mathrm{C}$ por $15 \mathrm{~s}$ e $30 \mathrm{~s}$ e com as doses de radiação de $0,660 \mathrm{~kJ} \mathrm{~m}^{-2}$ e 1,320 $\mathrm{kJ} \mathrm{m}^{-2}$. O controle do crescimento micelial de A. alternata e de $M$. roridum foi inferior com as doses de radiação e com a temperatura de $50{ }^{\circ} \mathrm{C}$ quando comparados aos demais tratamentos. Na redução do crescimento micelial de $F$. pallidoroseum, os tratamentos a $58{ }^{\circ} \mathrm{C}$ ou as doses de $0,660 \mathrm{~kJ} \mathrm{~m}^{-2}$ e $1,320 \mathrm{~kJ}$ $\mathrm{m}^{-2}$ foram mais eficiêntes, com controle superior a $88 \%$. Água aquecida a 58 ${ }^{\circ} \mathrm{C}$ por $15 \mathrm{~s}$ controlou UFCs e o crescimento micelial dos patógenos testados.

Palavras-chave adicionais: Cucumis melo, Mangifera indica, doenças pós-colheita, tratamentos físicos.

\section{ABSTRACT}

Nascimento, F.V.; Santos, M.C.; Valdebenito-Sanhueza, R.M.V.; Bartnicki, V.A. Hydrothermal and UV-C radiation in control of pathogens of mango and melon. Summa Phytopathologica, v.40, n.4, p.313-317, 2014.

Postharvest diseases are generally difficult to control and are responsible for significant losses in crops of mango (Mangifera indica) and melon (Cucumis melo L.) in Brazil. The main postharvest pathogens of melon are Alternaria alternata, Fusarium pallidoroseum and Myrothecium roridum, while those of mango fruits are Colletotrichum gloeosporioides and Lasiodiplodia theobromae. The aim of this study was to evaluate the sensitivity of propagules of these pathogens to hydrothermal and UV-C treatments. Conidia suspensions and mycelial discs of each pathogen were subjected to treatments of hot water at 50,55 and $58^{\circ} \mathrm{C}$ for $15 \mathrm{~s}$ and $30 \mathrm{~s}$ and UV-C radiation at doses of $0.330 \mathrm{~kJ} \mathrm{~m}^{-2}$, $0.660 \mathrm{~kJ} \mathrm{~m}^{-2}$ and $1.320 \mathrm{~kJ} \mathrm{~m}^{-2}$. After treatment and incubation for 72 and 48 $\mathrm{h}$, we assessed the number of colony formation units (CFUs) and the mycelial growth of pathogens, respectively. Treatments showed distinct efficiency among propagules and pathogens. The control of CFUs and mycelial growth of $C$. gloeosporioides and L.theobromae was greater than $88 \%$ with water heated to 55 or $58{ }^{\circ} \mathrm{C}$, independent of treatment time. For the same pathogens, a higher dose of radiation, $1.320 \mathrm{~kJ} \mathrm{~m}^{-2}$, controlled over $96 \%$ of the CFUs. However, control of the mycelial growth of these pathogens with UV-C radiation was lower when compared to the use of water heated to 55 or $58^{\circ} \mathrm{C}$. The control CFUs of A. alternata, M. roridum and $F$. pallidoroseum was higher with treatments of water heated to $55^{\circ} \mathrm{C}$ for $30 \mathrm{~s}, 58^{\circ} \mathrm{C}$ for $15 \mathrm{~s}$ and $30 \mathrm{~s}$ and with radiation doses of $0.660 \mathrm{~kJ} \mathrm{~m}^{-2}$ and $1.320 \mathrm{~kJ} \mathrm{~m}^{-2}$. The control of mycelial growth of A. alternata and $M$. roridum was lower with the radiation doses and temperature of $50{ }^{\circ} \mathrm{C}$ when compared to the other treatments. As regards the reduction in the mycelial growth of F. pallidoroseum, treatments at $58^{\circ} \mathrm{C}$ or the doses of 0.660 and 1.320 $\mathrm{kJ} \mathrm{m}^{-2}$ were more efficient and reached control of $88 \%$. Water heated to $58{ }^{\circ} \mathrm{C}$ for $15 \mathrm{~s}$ controlled the CFUs and the mycelial growth of the tested pathogens.

Additional keywords: Cucumis melo, Mangifera indica, postharvest diseases, physical treatments.

O Brasil é um dos principais exportadores de frutas frescas, com destaque para o melão e para a manga. No ano de 2012, o Brasil produziu 1.175.735 toneladas (t) de manga e 575.386 t de melão e, dentre as frutas frescas, estas duas estão entre as mais exportadas (9).

As doenças de pós-colheita causam perdas significativas de frutos em culturas tropicais destinadas à exportação. As podridões podem ocorrer por infecções diretas ou por consequência de infecções quiescentes, quando os sintomas aparecem principalmente com a maturação dos frutos (21). Dentre os principais patógenos causadores de podridões em melão destacam-se Alternaria alternata (Fr.) Keissler, 
Fusarium pallidoroseum (Cooke) Sacc. (sin: Fusarium semitectum Berk. \& Rav.) e Myrothecium roridum Tode ex Fries (20). Na manga, Colletotrichum gloeosporioides (Penz.) Sacc. e Lasiodiplodia theobromae (Pat.) Griffon \& Maubl. são responsáveis por causarem danos significativos (8).

A antracnose da manga, causada por $C$. gloeosporioides, é uma das principais doenças da cultura, especialmente na pós-colheita dos frutos (10). Nesse caso, o patógeno pode causar a podridão ainda no pomar ou permanecer latente e se manifestar apenas durante o amadurecimento do fruto. A podridão peduncular da manga é causada pelo fungo $L$. theobromae. O patógeno penetra no fruto pelo pedúnculo ou por ferimentos, causando rápido apodrecimento das áreas infectadas (8). O fungo $M$. roridum é um habitante natural do solo capaz de parasitar vários hospedeiros, dentre os quais se destaca o meloeiro. O patógeno causa a podridão-da-cratera nos frutos. No Brasil, ainda não existem fungicidas registrados para o controle da doença, tornando-a de difícil manejo (13). O fungo F. pallidoroseum sobrevive saprofiticamente em restos de culturas e é responsável pela podridão-do-pedúnculo do melão. A infecção inicia-se na região peduncular ou em ferimentos em outras partes do fruto (20). As espécies do gênero Alternaria estão nos grupos capazes de causar infecções quiescentes na pós-colheita de diversas frutas. A. alternata é o agente causal da podridão-de-alternaria, de modo que a infecção se dá através de aberturas naturais, principalmente lenticelas, ou por ferimentos (16).

O controle químico com fungicidas, inibidores de amadurecimento, controle biológico por antagonistas, controle físico pelo uso de refrigeração, tratamento térmico, radiação, atmosfera controlada e modificada e a indução de resistência utilizando elicitores bióticos e abióticos são alguns métodos utilizados para redução de perdas póscolheita de frutos causadas por patógenos (17). De acordo com Oliveira (14), a utilização de fungicidas pode causar contaminação dos frutos, além de selecionar estirpes resistentes dos fungos. Assim, se torna necessário o estudo de métodos alternativos de controle que sejam eficientes e que permitam o consumo de alimentos livres de resíduos.

O tratamento hidrotérmico é realizado na cultura da manga como medida quarentenária contra a mosca-das-frutas, Ceratitis capitata (Wied.), sendo também eficiente no controle da antracnose e da podridão peduncular. $\mathrm{O}$ método consiste na imersão das frutas em água a $46,1^{\circ} \mathrm{C}$ durante 75 min para mangas com peso inferior a $425 \mathrm{~g}$ e 90 min para aquelas com mais de $425 \mathrm{~g}$ (1). Outros estudos relatam que o uso de água aquecida a $55^{\circ} \mathrm{C}$ por $5 \mathrm{~min}$ associado à refrigeração reduz a severidade da antracnose em manga 'Haden', prolongando sua vida de prateleira (10). Em maçãs, a imersão em água aquecida inibe o desenvolvimento de Botryosphaeria dothidea (Moug. ex Fr.) Ces. $\&$ De Not. e reduz a severidade da podridão branca (11), enquanto que a aspersão de maçãs com água aquecida a $53{ }^{\circ} \mathrm{C}$ por $30 \mathrm{~s}$ reduz a porcentagem de podridão branca (15).

A radiação UV-C é outro método físico utilizado na indústria alimentar. A sua ação germicida é uma forma eficaz de descontaminação microbiana de superfícies e embalagens e pode ser aplicada em vegetais na pós-colheita para redução de propágulos de patógenos (4). De acordo com Demirci \& Panico (7), o efeito germicida da radiação UV-C pode ser ocasionado pela destruição de estruturas do patógeno, inibição da sua germinação ou do seu desenvolvimento, pela desnaturação proteica e desorganização da membrana plasmática. Estudos realizados em maçãs mostram que a radiação UV-C também pode agir como indutor de resistência à podridão amarga causada pelo fungo C. gloeosporioides (19).

Cia et al. (6) e Bartnicki et al. (3) mostraram que a radiação UV-C é capaz de reduzir a incidência de $C$. gloeosporioides em uvas e de
Cryptosporiopsis perennans (Zeller \& Childs) Wollenweber em maçãs, respectivamente. Além disso, Bartnicki et al. (3) verificaram que a água aquecida a $50^{\circ} \mathrm{C}$ por $15 \mathrm{~s}$ foi eficiente no controle deste último patógeno, agente causal da podridão olho-de-boi em maçãs. Em mangas 'Tommy Atkins' inoculadas com $B$. dothidea, e submetidas à dose de $3,0 \mathrm{~kJ} \mathrm{~m}^{-2}$, Terao et al. (22) observaram redução de $70 \%$ da severidade da podridão em frutos armazenados a $10{ }^{\circ} \mathrm{C}$ por 15 dias mais 2 dias a $22^{\circ} \mathrm{C}$.

Os estudos existentes mostram que a hidrotermia e a radiação UV-C apresentam potencial para uso em pós-colheita de frutas e hortaliças, contudo existem poucos relatos que comparem às vantagens desses métodos para o controle dos patógenos mais importantes de manga e melão. Assim, o objetivo desse trabalho foi verificar a sensibilidade in vitro à hidrotermia e à radiação UV-C dos propágulos de $A$. alternata, F. pallidoroseum e $M$. roridum, que causam podridão na pós-colheita em melão, e dos patógenos $C$. gloeosporioides e $L$. theobromae, responsáveis por causarem danos em manga.

\section{MATERIAL E MÉTODOS}

Os experimentos foram conduzidos no Centro de Pesquisa Proterra (CPPro), localizado em Vacaria, RS. Para avaliar a sensibilidade dos propágulos foram selecionados dois patógenos de manga $(C$. gloeosporioides e L. theobromae) e três do melão (A. alternata, $F$. pallidoroseum e $M$. roridum), que pertencem à coleção de fungos da Embrapa Semi-Árido (CPATSA).

A produção de inóculo de $L$. theobromae foi obtida pelo cultivo do fungo em placas de Petri com meio de cultura BDA coberto com disco de papel filtro esterilizado. Para as placas foram transferidos discos de BDA colonizados com o patógeno, as quais foram incubadas durante 15 dias a $23 \pm 1{ }^{\circ} \mathrm{C}$ sob luz fluorescente (tipo luz do dia). Após o período de incubação, o papel filtro foi dividido em segmentos de aproximadamente $1 \mathrm{~cm}^{2}$ e colocado em um almofariz com $10 \mathrm{~mL}$ de água destilada e esterilizada (ADE) e macerado com pistilo (15). Com auxílio de um hemacitômetro foi obtida a suspensão do patógeno na concentração de $10^{3}$ conídios. $\mathrm{mL}^{-1}$.

Os outros quatro patógenos foram cultivados em BDA durante 15 dias sob iluminação contínua de luz fluorescente (tipo luz do dia) e $23 \pm 1{ }^{\circ} \mathrm{C}$. As placas com as colônias foram inundadas com $20 \mathrm{~mL}$ de ADE suplementada com TWEEN $80(0,001 \%)$ e raspadas com uma pinça esterilizada. A suspensão foi ajustada para a concentração de $10^{3}$ conídios. $\mathrm{mL}^{-1}$

Para a obtenção de micélio, colônias desenvolvidas em BDA durante sete dias a $23 \pm 1{ }^{\circ} \mathrm{C}$ com fotoperíodo de $12 \mathrm{~h}$ foram utilizadas. Da margem de cada colônia foram obtidos discos de 3,5 $\mathrm{mm}$ de diâmetro do BDA colonizado com cada patógeno.

O tratamento hidrotérmico consistiu na imersão de tubos de ensaio contendo $3 \mathrm{~mL}$ da suspensão de conídios ou de béquer com $5 \mathrm{~mL}$ de $\mathrm{ADE}$ e discos de micélio em água aquecida. As temperaturas utilizadas foram $50{ }^{\circ} \mathrm{C}, 55^{\circ} \mathrm{C}$ e $58{ }^{\circ} \mathrm{C}$ e períodos de exposição de $15 \mathrm{~s}$ e $30 \mathrm{~s}$, contados a partir da imersão. Após o tratamento, cada tubo ou béquer foi transferido para água com gelo $\left(\approx 3^{\circ} \mathrm{C}\right)$, para deter a exposição das estruturas às altas temperaturas. Para o tratamento com radiação UV-C foram preparadas placas de Petri de $5 \mathrm{~cm}$ de diâmetro, contendo $3 \mathrm{~mL}$ da suspensão de conídios e discos de micélio, os quais foram então expostos à radiação UV-C pelo período de $15 \mathrm{~s}, 30 \mathrm{~s}$ e $60 \mathrm{~s}$, o que determinou a exposição à radiância de $0,330 \mathrm{~kJ} \mathrm{~m}^{-2}, 0,660 \mathrm{~kJ} \mathrm{~m}^{-2} \mathrm{e}$ $1,320 \mathrm{~kJ} \mathrm{~m}^{-2}$, respectivamente. A radiação UV-C foi aferida conforme metodologia descrita por Bartnicki et al. (3).

Após os tratamentos hidrotérmicos ou com radiação UV-C, 
alíquotas de $0,1 \mathrm{~mL}$ das suspensões de conídios e os discos de micélio foram transferidos para placas de Petri contendo meio de cultura BDA, as quais foram incubadas a $23 \pm 1{ }^{\circ} \mathrm{C}$, sob luz fluorescente contínua. As placas com suspensão dos patógenos foram avaliadas após $72 \mathrm{~h}$ através da contagem do número de unidades formadoras de colônias (UFCs). Após 48 h registrou-se o diâmetro das colônias desenvolvidas do micélio.

O delineamento experimental utilizado foi inteiramente casualizado com dez tratamentos e três repetições, sendo cada parcela constituída por um tubo de ensaio com a suspensão de conídios. Na avaliação do crescimento micelial, as parcelas foram constituídas de uma placa ou béquer contendo três discos de BDA com micélio do patógeno. Os dados obtidos foram expressos em porcentagem de controle e submetidos à análise de variância após transformação para arco-seno $[(\mathrm{x}+1) / 100]^{1 / 2}$. As médias obtidas foram comparadas pelo teste Tukey a $5 \%$ de probabilidade.

\section{RESULTADOS E DISCUSSÃO}

A redução da sobrevivência de conídios e do crescimento micelial dos cinco patógenos foi obtida em todos os tratamentos hidrotérmicos e de radiação UV-C, mas a porcentagem de controle variou dependendo do patógeno.

Os conídios de $A$. alternata foram sensíveis às temperaturas do tratamento hidrotérmico, sendo o controle superior a $98 \%$, independente do tempo e da temperatura do tratamento. $\mathrm{O}$ controle do crescimento micelial foi maior com o aumento do tempo de exposição de $15 \mathrm{~s}$ para $30 \mathrm{~s}$ na temperatura de $50{ }^{\circ} \mathrm{C}$, de modo que alcançou $100 \%$ a $55^{\circ} \mathrm{C}$ e $58^{\circ} \mathrm{C}$, independente do tempo. Para o mesmo patógeno, o tratamento com radiação UV-C controlou mais de $95 \%$ das UFCs nas doses de $0,660 \mathrm{~kJ} \mathrm{~m}^{-2} \mathrm{e} 1,320 \mathrm{~kJ} \mathrm{~m}^{-2}$, sendo estes tratamentos tão eficientes quanto com água aquecida. Contudo, o crescimento micelial teve inibição de apenas $44 \%$ na maior dose de radiação UV-C, tratamento este inferior aos de hidrotermia a $55^{\circ} \mathrm{C}$ e $58^{\circ} \mathrm{C}$ (Tabela 1 ).

Para o patógeno $F$. pallidoroseum, o tratamento a $50{ }^{\circ} \mathrm{C}$ foi pouco eficiente $(<30 \%)$, tanto no controle das UFCs quanto do crescimento micelial. Na temperatura de $55^{\circ} \mathrm{C}$, a inibição de UFCs e do crescimento micelial foi maior do que a $50{ }^{\circ} \mathrm{C}$, porém a $55^{\circ} \mathrm{C}$ não houve diferença entre os tempos de tratamento. Nesta mesma temperatura por $30 \mathrm{~s}$, o efeito sobre as UFCs foi igual aos tratamentos a $58{ }^{\circ} \mathrm{C}$, com controle superior a $90 \%$. Nos tratamentos a $58^{\circ} \mathrm{C}$ por $15 \mathrm{~s}$ e $30 \mathrm{~s}$, os propágulos, tanto UFCs quanto micélio, apresentaram sensibilidade superior a 98 $\%$, sendo os melhores tratamentos de hidrotermia para o controle do crescimento micelial. O controle de UFCs foi superior a $90 \%$ com o uso da radiação UV-C e não diferiu entre as doses utilizadas. As doses de radiação foram tão eficientes quanto os melhores tratamentos com água aquecida no controle de UFCs de F. pallidoroseum. Enquanto isso, a inibição do crescimento micelial foi superior com as doses de 0,660 $\mathrm{kJ} \mathrm{m}^{-2}$ e $1,320 \mathrm{~kJ} \mathrm{~m}^{-2}$ de radiação UV-C, quando comparadas a dose de $0,330 \mathrm{~kJ} \mathrm{~m}^{-2}$. O uso de água aquecida a $58^{\circ} \mathrm{C}$ por $15 \mathrm{~s}$ ou $30 \mathrm{~s}$, ou a radiação UV-C de $0,660 \mathrm{~kJ} \mathrm{~m}^{-2}$ ou $1,320 \mathrm{~kJ} \mathrm{~m}^{-2}$ foram os tratamentos mais eficientes para o controle do micélio de F. pallidoroseum.

Os propágulos do fungo $M$. roridum mostraram-se sensíveis ao tratamento hidrotérmico e a radiação UV-C (Tabela 1). O controle de UFCs deste patógeno foi eficiente com $55^{\circ} \mathrm{C}$ e $58^{\circ} \mathrm{C}$, independente do tempo, e com as doses de radiação UV-C de $0,660 \mathrm{~kJ} \mathrm{~m}^{-2} \mathrm{e} 1,320 \mathrm{~kJ} \mathrm{~m}^{-2}$. Por outro lado, o controle do micélio foi eficiente apenas com $55^{\circ} \mathrm{C}$ e $58^{\circ} \mathrm{C}$ por $15 \mathrm{~s}$ ou $30 \mathrm{~s}$, sendo este de $100 \%$. O tratamento com radiação UV-C na dose de $1,320 \mathrm{~kJ} \mathrm{~m}^{-2}$ inibiu $72 \%$ do crescimento micelial, de modo que as doses de $0,330 \mathrm{~kJ} \mathrm{~m}^{-2}$ e de $0,660 \mathrm{~kJ} \mathrm{~m}^{-2}$ apresentaram controle inferior a $36 \%$.

A sensibilidade de conídios de C. gloeosporioides aos tratamentos foi maior que a do micélio (Tabela 2). Enquanto na água aquecida a $50{ }^{\circ} \mathrm{C}$ o controle de conídios foi de $92 \%$ e $97 \%$ durante 15 s e $30 \mathrm{~s}$, o controle do crescimento do micélio foi de $12 \%$ e $60 \%$, respectivamente. O maior controle (próximo de $100 \%$ ) de conídios e do micélio deste patógeno foi obtido pela água aquecida a $55^{\circ} \mathrm{C}$ ou $58^{\circ} \mathrm{C}$, tanto em $15 \mathrm{~s}$ como em $30 \mathrm{~s}$. Já no caso da radiação UV-C, os tratamentos com 0,330 $\mathrm{kJ} \mathrm{m}^{-2}$ e $0,660 \mathrm{~kJ} \mathrm{~m}^{-2}$ foram inferiores ao de $1,320 \mathrm{~kJ} \mathrm{~m}^{-2}$ na inibição dos conídios, de modo que este último tratamento não diferiu dos melhores com água aquecida. Para o controle do micélio, mesmo na maior dose de radiação $\left(1,320 \mathrm{~kJ} \mathrm{~m}^{-2}\right)$, o controle foi de apenas $47 \%$.

O tratamento hidrotérmico a $50{ }^{\circ} \mathrm{C}$ por $15 \mathrm{~s}$ controlou apenas $35 \%$ das UFCs de L. theobromae, sendo inferior aos tratamentos a $55^{\circ} \mathrm{C}$ e a $58^{\circ} \mathrm{C}$ e com radiação UV-C, os quais apresentaram controle superior

Tabela 1. Controle (\%) de unidades formadoras de colônias (UFCs) e do crescimento do micélio de patógenos de melão (A. alternata, F. pallidoroseum e M. roridum) submetidos aos tratamentos hidrotérmicos e de radiação UV-C. Vacaria, 2013.

\begin{tabular}{|c|c|c|c|c|c|c|c|c|c|c|c|c|}
\hline \multirow{3}{*}{$\begin{array}{l}\text { Tratamentos } \\
50^{\circ} \mathrm{C}-15 \mathrm{~s}\end{array}$} & \multicolumn{4}{|c|}{ A. alternata } & \multicolumn{4}{|c|}{ F. pallidoroseum } & \multicolumn{4}{|c|}{ M. roridum } \\
\hline & \multicolumn{2}{|c|}{$\begin{array}{c}\text { Controle de UFCs } \\
(\%)^{1}\end{array}$} & \multicolumn{2}{|c|}{$\begin{array}{l}\text { Controle do } \\
\text { micélio }(\%)^{2}\end{array}$} & \multicolumn{2}{|c|}{$\begin{array}{c}\text { Controle de UFCs } \\
(\%)^{1}\end{array}$} & \multicolumn{2}{|c|}{$\begin{array}{l}\text { Controle do micélio } \\
\qquad(\%)^{2}\end{array}$} & \multicolumn{2}{|c|}{$\begin{array}{c}\text { Controle de UFCs } \\
(\%)^{1}\end{array}$} & \multicolumn{2}{|c|}{$\begin{array}{l}\text { Controle do } \\
\text { micélio }(\%)^{2}\end{array}$} \\
\hline & 98,4 & $\mathrm{a}$ & 21,9 & $\mathrm{~d}$ & 12,3 & $\mathrm{c}$ & 6,4 & $\mathrm{c}$ & 44,4 & $\mathrm{c}$ & 45,8 & $\mathrm{~cd}$ \\
\hline $50^{\circ} \mathrm{C}-30 \mathrm{~s}$ & 98,9 & $\mathrm{a}$ & 61,9 & $\mathrm{~b}$ & 29,4 & $\mathrm{c}$ & 10,0 & $\mathrm{c}$ & 76,2 & $\mathrm{~b}$ & 75,6 & $\mathrm{~b}$ \\
\hline $55^{\circ} \mathrm{C}-15 \mathrm{~s}$ & 100,0 & $\mathrm{a}$ & 100,0 & a & 69,2 & $\mathrm{~b}$ & 48,4 & $\mathrm{~b}$ & 99,4 & $\mathrm{a}$ & 100,0 & $\mathrm{a}$ \\
\hline $55^{\circ} \mathrm{C}-30 \mathrm{~s}$ & 100,0 & $\mathrm{a}$ & 100,0 & a & 90,2 & $a b$ & 48,4 & $\mathrm{~b}$ & 100,0 & $\mathrm{a}$ & 100,0 & $\mathrm{a}$ \\
\hline $58^{\circ} \mathrm{C}-15 \mathrm{~s}$ & 100,0 & $\mathrm{a}$ & 100,0 & $\mathrm{a}$ & 100,0 & $\mathrm{a}$ & 100,0 & a & 99,7 & a & 100,0 & $\mathrm{a}$ \\
\hline $58^{\circ} \mathrm{C}-30 \mathrm{~s}$ & 100,0 & $\mathrm{a}$ & 100,0 & $\mathrm{a}$ & 98,6 & a & 100,0 & $\mathrm{a}$ & 100,0 & $\mathrm{a}$ & 100,0 & $\mathrm{a}$ \\
\hline $0,330 \mathrm{~kJ} \mathrm{~m}^{-2}$ & 76,4 & $\mathrm{~b}$ & 30,7 & $\mathrm{~cd}$ & 91,7 & $a b$ & 46,4 & $\mathrm{~b}$ & 87,2 & $\mathrm{~b}$ & 35,8 & $\mathrm{~d}$ \\
\hline $0,660 \mathrm{~kJ} \mathrm{~m}^{-2}$ & 95,1 & a & 38,8 & $\mathrm{~cd}$ & 100,0 & a & 88,4 & a & 100,0 & a & 31,4 & $\mathrm{~d}$ \\
\hline $1,320 \mathrm{~kJ} \mathrm{~m}^{-2}$ & 96,2 & $\mathrm{a}$ & 44,4 & $\mathrm{bc}$ & 99,6 & $\mathrm{a}$ & 100,0 & $\mathrm{a}$ & 100,0 & $\mathrm{a}$ & 71,8 & bc \\
\hline $\mathrm{F}$ p/ tratamentos & \multicolumn{2}{|c|}{12,6} & \multicolumn{2}{|c|}{145,3} & \multicolumn{2}{|c|}{34,7} & \multicolumn{2}{|c|}{41,4} & \multicolumn{2}{|c|}{46,7} & \multicolumn{2}{|c|}{50,8} \\
\hline CV (\%) & \multicolumn{2}{|c|}{5,4} & \multicolumn{2}{|c|}{6,4} & \multicolumn{2}{|c|}{11,4} & \multicolumn{2}{|c|}{14,6} & \multicolumn{2}{|c|}{5,6} & \multicolumn{2}{|c|}{9,0} \\
\hline
\end{tabular}

Médias seguidas pela mesma letra, na coluna, não diferem significativamente pelo teste de Tukey a 5\% de probabilidade. ${ }^{1}$ Média de três repetições, cada uma constituída por duas placas com colônias. ${ }^{2}$ Média de três repetições, cada uma composta por uma placa com três discos de micélio. 
Tabela 2. Controle (\%) de unidades formadoras de colônias (UFCs) e do crescimento do micélio de patógenos de manga (C. gloeosporioides e L. theobromae), com tratamento hidrotérmico e radiação UV-C. Vacaria, 2013.

\begin{tabular}{|c|c|c|c|c|c|c|c|c|}
\hline \multirow{3}{*}{$\begin{array}{l}\text { Tratamento } \\
50^{\circ} \mathrm{C}-15 \mathrm{~s}\end{array}$} & \multicolumn{4}{|c|}{ C. gloeosporioides } & \multicolumn{4}{|c|}{ L. theobromae } \\
\hline & \multicolumn{2}{|c|}{$\begin{array}{c}\text { Controle de UFCs } \\
\qquad \%)^{1}\end{array}$} & \multicolumn{2}{|c|}{ Controle do micélio $(\%)^{2}$} & \multicolumn{2}{|c|}{$\begin{array}{c}\text { Controle de UFCs } \\
(\%)\end{array}$} & \multicolumn{2}{|c|}{ Controle do micélio (\%) } \\
\hline & 91,7 & $\mathrm{~b}$ & 12,1 & $\mathrm{e}$ & 35,1 & $\mathrm{~b}$ & 0,2 & $\mathrm{~b}$ \\
\hline $50^{\circ} \mathrm{C}-30 \mathrm{~s}$ & 97,4 & $a b$ & 59,6 & $\mathrm{~b}$ & 59,6 & $a b$ & 5,5 & $\mathrm{~b}$ \\
\hline $55^{\circ} \mathrm{C}-15 \mathrm{~s}$ & 99,6 & $\mathrm{a}$ & 100,0 & $\mathrm{a}$ & 98,2 & a & 100,0 & a \\
\hline $55^{\circ} \mathrm{C}-30 \mathrm{~s}$ & 99,7 & a & 100,0 & $\mathrm{a}$ & 98,4 & a & 100,0 & $\mathrm{a}$ \\
\hline $58^{\circ} \mathrm{C}-15 \mathrm{~s}$ & 100,0 & a & 100,0 & a & 98,2 & a & 88,9 & a \\
\hline $58^{\circ} \mathrm{C}-30 \mathrm{~s}$ & 99,7 & a & 100,0 & a & 100,0 & a & 100,0 & a \\
\hline $0,330 \mathrm{~kJ} \mathrm{~m}^{-2}$ & 72,5 & $\mathrm{c}$ & 24,0 & de & 100,0 & $\mathrm{a}$ & 7,4 & $\mathrm{~b}$ \\
\hline $0,660 \mathrm{~kJ} \mathrm{~m}^{-2}$ & 73,4 & $\mathrm{c}$ & 34,1 & $\mathrm{~cd}$ & 100,0 & $\mathrm{a}$ & 7,6 & $\mathrm{~b}$ \\
\hline $1,320 \mathrm{~kJ} \mathrm{~m}^{-2}$ & 96,1 & $a b$ & 47,4 & $\mathrm{bc}$ & 100,0 & a & 8,4 & $\mathrm{~b}$ \\
\hline $\mathrm{F} \mathrm{p} /$ tratamentos & \multicolumn{2}{|c|}{18,1} & \multicolumn{2}{|c|}{181,4} & \multicolumn{2}{|c|}{7,6} & \multicolumn{2}{|c|}{90,0} \\
\hline CV $(\%)$ & \multicolumn{2}{|c|}{6,3} & \multicolumn{2}{|c|}{6,3} & \multicolumn{2}{|c|}{15,5} & \multicolumn{2}{|c|}{15,4} \\
\hline
\end{tabular}

Médias seguidas pela mesma letra, na coluna, não diferem significativamente pelo teste de Tukey a 5\% de probabilidade. ${ }^{1}$ Média de três repetições, cada uma constituída por duas placas com colônias. ${ }^{2}$ Média de três repetições, cada uma composta por uma placa com três discos de micélio.

a $98 \%$ (Tabela 2). O crescimento micelial foi inibido acima de $88 \%$ pelos tratamentos a $55^{\circ} \mathrm{C}$ e $58{ }^{\circ} \mathrm{C}$, sendo superiores aos tratamentos a $50^{\circ} \mathrm{C}$ e com radiação UV-C, os quais apresentaram controle ineficiente, uma vez que foi inferior a $9 \%$.

Os conídios dos patógenos de melão (A. alternata, F. pallidoroseum e $M$. roridum) e de manga (C. gloeosporioides e L. theobromae) apresentaram elevada sensibilidade ao tratamento hidrotérmico, sendo a porcentagem de controle superior a $88 \% \operatorname{com} 55^{\circ} \mathrm{C}$ e $58^{\circ} \mathrm{C}$ nos dois períodos de exposição ( $15 \mathrm{~s}$ e $30 \mathrm{~s}$ ), exceto para $F$. palidoroseum na temperatura de $55^{\circ} \mathrm{C}$. Estes resultados corroboram com os de Bruton \& Duthie (5), que observaram que a imersão por $60 \mathrm{~s}$ em água aquecida a $57^{\circ} \mathrm{C}$ associada ao uso de fungicidas foi capaz de controlar a podridãode-fusário em frutos do meloeiro o que não foi possível em temperaturas menores. Também, Barkai-Golan \& Phillips (2) afirmam que fungos que causam podridão em pós-colheita de melão são controlados em temperaturas entre $57^{\circ} \mathrm{C}$ e $63^{\circ} \mathrm{C}$ por $30 \mathrm{~s}$, porém nos resultados obtidos aqui se observou que com $58{ }^{\circ} \mathrm{C}$ por $15 \mathrm{~s}$ foi possível obter controle eficiente dos propágulos dos patógenos. A redução de $30 \mathrm{~s}$ para $15 \mathrm{~s}$ no tempo do tratamento facilita a logística no processamento dos frutos e o rendimento na embalagem será superior. Lima et al. (10) verificaram que $5 \mathrm{~min}$ a $55^{\circ} \mathrm{C}$, utilizado para reduzir a severidade da antracnose em manga, não afetou as propriedades físico-químicas dos frutos, e, Silveira et al. (18) não verificaram alterações na polpa de melão submetido ao tratamento de $60^{\circ} \mathrm{C}$ por $60 \mathrm{~s}$.

A radiação UV-C possui efeito germicida sobre microorganismos (3), de modo que neste trabalho as doses de $0,660 \mathrm{~kJ} \mathrm{~m}^{-2}$ e $1,320 \mathrm{~kJ} \mathrm{~m}^{-2}$ controlaram acima de $95 \%$ as UFCs dos patógenos de manga e melão utilizados nestes experimentos, com exceção de C. gloeosporioides na dose de $0,660 \mathrm{~kJ} \mathrm{~m}^{-2}$, cujo controle foi 73,4 \%. Da mesma forma, Bartnicki et al. (3) observaram controle semelhante dos conídios do agente causal da podridão olho-de-boi, $C$. perennans, com doses de $0,750 \mathrm{~kJ} \mathrm{~m}^{-2}$ a $3,000 \mathrm{~kJ} \mathrm{~m}^{-2}$. Para os patógenos A. alternata, M. roridum e C. gloeosporioides, o aumento da dose resultou no incremento da eficiência do tratamento, concordando com os resultados de Marquenie et al. (12) que observaram aumento na eficiência da radiação UV-C no controle de conídios de $B$. cinerea e $M$. fructigena com o incremento na dose utilizada de 0,1 a $15 \mathrm{~kJ} \mathrm{~m}^{-2}$.

Neste estudo, doses de radiação UV-C entre 0,330 e $1,320 \mathrm{~kJ}$ $\mathrm{m}^{-2}$, tiveram pouco efeito sobre o crescimento micelial dos fungos $C$. gloeosporiodes e $L$. theobromae, da mesma forma que o observado por Terao et al. (22) com doses semelhantes. Este autores observaram efeito da radiação UV-C sobre o micélio de C. gloeosporioides somente com doses de $5,0 \mathrm{~kJ} \mathrm{~m}^{-2}$ ou acima, sendo que o tratamento de mangas cv. Tommy Atkins com doses de radiação UV-C acima de 5,0 kJ m ${ }^{-2}$ causaram danos na epiderme dos frutos e incrementaram a severidade de podridões (22).

Os tratamentos avaliados apresentaram eficiência distinta entre os propágulos e a redução na viabilidade dos conídios foi maior do que a observada para o crescimento micelial.

Os patógenos diferiram quanto à sensibilidade à termoterapia e à radiação UV-C e o controle eficiente dos conídios de A. alternata, $M$. roridum e F. pallidoroseum - patógenos de melão - é obtido com $55^{\circ} \mathrm{C}$ por $30 \mathrm{~s}, 58^{\circ} \mathrm{C}$ por $15 \mathrm{~s}$ ou com as doses de radiação UV-C de $0,660 \mathrm{~kJ}$ $\mathrm{m}^{-2}$ ou $1,320 \mathrm{~kJ} \mathrm{~m}^{-2}$. O crescimento micelial dos mesmos patógenos foi inibido com $58^{\circ} \mathrm{C}$ por $15 \mathrm{~s}$ ou $30 \mathrm{~s}$. Os propágulos de C. gloeosporioides e L. theobromae - patógenos da manga - foram controlados de maneira eficaz com $55^{\circ} \mathrm{C}$ por $15 \mathrm{~s}$ ou $30 \mathrm{~s}$ e $58^{\circ} \mathrm{C}$ por $15 \mathrm{~s}$ ou $30 \mathrm{~s}$.

Neste trabalho demonstrou-se o efeito direto da hidrotermia e da radiação UV-C sobre os patógenos de manga e melão, porém adicionalmente estes métodos de controle podem induzir resistência nos frutos, inibindo infecções quiescentes de patógenos $(2,19)$. Na manga foi verificada a viabilidade do uso de doses de radiação UV-C inferiores a $3,0 \mathrm{~kJ} \mathrm{~m}^{-2}(22)$.

\section{AGRADECIMENTOS}

Agradecemos à Embrapa Semi-Árido (CPATSA) pela disponibilização dos isolados. 


\section{REFERÊNCIAS BIBLIOGRÁFICAS}

1. Assis, J.S.; Lima, M.A.C. Produção integrada de manga: manejo pós-colheita e rastreabilidade. Petrolina: Embrapa Semi-Árido, 2008. 12p. (Circular Técnica, 89).

2. Barkai-Golan, R; Phillips, D.J. Postharvest heat treatment of fresh fruits and vegetables for decay control. Plant Disease, Saint Paul, v.75, n.2, p.1085-1089, 1991.

3. Bartnicki, V.A.; Valdebenito-Sanhueza, R.M.; Amarante, C.V.T.; Castro, L.A.S.; Rizzatti, M.R.; Souza, J.A.V. Água aquecida e radiação UV-C no controle pós-colheita de Cryptosporiopsis perennans em maçãs. Pesquisa Agropecuária Brasileira, Brasília, v.45, n.2, p.124-131, 2010.

4. Bintsis, T.; Litopoulou-Tzanetaki, E.; Robinson, R. K. Existing and potential applications of ultraviolet light in the food industry - a critical review. Journal of the Science of Food and Agriculture, London, v.80, p.637-645, 2000.

5. Bruton, B.D.; Duthie, J.A. Fusarium rot. In: Zitter, T.A., Hopkins, D.L., Thomas, C.E. (Eds.) Compendium of cucurbit diseases. Saint Paul. APS Press. 1996. p.50-51

6. Cia, P.; Benato, E.A.; Valentini, S.R.T.; Anjos, V.D.A.; Ponzo, F.S.; Sanches, J.; Terra, M.M. Radiação ultravioleta no controle pós-colheita de Colletotrichum gloeosporioides em uva 'Niagara Rosada'. Bragantia, Campinas, v.68, n.4, p.1009-1015, 2009.

7. Demirci, A.; Panico, L. Pulsed ultraviolet light. Food Science and Technology International, London, v. 14, n.5, p.443-446, 2008.

8. Fischer, I.H.; Arruda, M.C.; Almeida, A.M.; Galli, J.A.; Bertani, R.M.A.; Jerônimo, E.M. Doenças pós-colheita em variedades de manga cultivadas em Pindorama, São Paulo. Revista Brasileira de Fruticultura, Jaboticabal, v.31, n.2, p. 352-359, 2009.

9. Instituto Brasileiro de Geografia e Estatística. Produção Agrícola Municipal: Culturas Temporárias e Permanentes 2012. Disponível em: <http:// www.ibge.gov.br>. Acesso em: 06 out. 2014.

10. Lima, L.C.; Dias, M.S.C.; Castro, M.V.; Ribeiro Júnior, P.M.; Silva, E.B. Controle da antracnose e qualidade de mangas (Mangifera indica L.) cv. Haden, após tratamento hidrotérmico e armazenamento refrigerado em atmosfera modificada. Ciência e Agrotecnologia, Lavras, v.31, n.2, p.298-304, 2007.

11. Lunardi, R., Sanhueza, R.M.V., Bender, R.J. Imersão em água quente no controle pós-colheita da podridão branca em maçãs cv. Fuji. Fitopatologia Brasileira, Brasília, v.28, n.4, p.431-434, 2003.
12. Marquenie, D.; Lammertyn, J.; Geeraerd, A.H.; Soontjens, C.; Van Impe, J.F.; Nicolai, B.M.; Michiels, C.W. Inactivation of conidia of Botrytis cinerea and Monilinia fructigena using $\mathrm{UV}-\mathrm{C}$ and heat treatment. International Journal of Food Microbiology, Amsterdam, v.74, p.27-35, 2002.

13. Noronha, M.A.; Michereff, S.J.; Moreira, P.A.A.; Xavier Filha, M.S.; Sales Junior, R.; Mizubuti, E.S.G. Variabilidade de isolados de Myrothecium roridum provenientes de meloeiro cultivado no Estado do Rio Grande do Norte. Tropical Plant Pathology, Brasília, v.33, n.6, p.432-438, 2008.

14. Oliveira, M.J. Epidemiologia da podridão-de-fusário em frutos de meloeiro. 2007. 59f. Dissertação (Mestrado em Fitossanidade) - Universidade Federal Rural de Pernambuco, Recife.

15. Oster, A.H. Tratamento com calor no controle de Botryosphaeria dothidea (Moug.) Ces. \& De Not.) em maçãs cv. Fuji. 2004. 96f. Tese (Doutorado em Fitotecnia) - Universidade Federal do Rio Grande do Sul, Porto Alegre.

16. Senhor, R.F.; Carvalho, J.N.; Souza, P.A.; Andrade Neto, R.C.; Pinto, A.C. Eficiência de diferentes fungicidas no controle de Alternaria alternata, agente causal da podridão pós-colheita em frutos do meloeiro. Caatinga, Mossoró, v.22, n.3, p.40-45, 2009

17. Silveira, A.C.; Aguayob, E.; Chisaric, M.; Artésb, F. Calcium salts and heat treatment for quality retention of fresh-cut 'Galia' melon. Postharvest Biology and Technology, Amsterdan, v.62, p.77-84, 2011.

18. Silveira, N.S.S.; Michereff, S.J.M.; Silva, I.L.S.S.; Oliveira, S.M.A. Doenças fúngicas pós-colheita em frutas tropicais: patogênese e controle. Caatinga, Mossoró, v.18, n.4, p.283-299, 2005.

19. Stevens, C; Khan, V.A.; Wilson, C.L. The effect of fruit orientation of postharvest commodities following low dose ultraviolet light-C treatment on host induced resistance to decay. Crop Protection, Oxford, v.24, n.8, p.756-759, 2005

20. Terao, D.; Oliveira, S.M.A; Viana, F.M.P.; Saraiva, A.C.M. Estratégias de controle de podridões em pós-colheita de melão: uma revisão. Fortaleza: Embrapa Agroindústria Tropical, 2008. 56p. (Documentos, 112).

21. Terao, D.; Batista, D.C.; Barbosa, M.A.G.; Barros, E. S. Manejo de doenças pós-colheita em frutas tropicais. Tropical Plant Pathology, Brasília, v.34, supl., p. xxiv-xxv, 2009 (Mesa Redonda).

22. Terao, D.; Campos, J.S.C.; Benato, E.A.; Hashimoto, J.M. Alternative strategy on control of postharvest diseases of mango (Mangifera indica L.) by use of low ose of ultraviolet-C irradiation, Food Engineering Reviews Berlim, 2014. Disponível em: $<$ http://link.springer.com/article/10.1007\%2 Fs12393-014-9089-4>. Acesso em: 13 out. 2014. 